\title{
ANALISIS HUBUNGAN KECEPATAN TERHADAP KECELAKAAN LALU-LINTAS DI KOTA BANJARMASIN
}

\section{Speed Relationship Analysis on Traffic Accidents in Banjarmasin City}

\author{
Huddan Rahmani \\ Program Studi Teknik Sipil \\ Universitas Islam Kalimantan MAB \\ Jalan adhyaksa No.2 Banjarmasin \\ Kalimantan Selatan \\ uwa.hudan58@gmail.com \\ Akhmad Gazali \\ Program Studi Teknik Sipil \\ Universitas Islam Kalimantan MAB \\ Jalan adhyaksa No.2 Banjarmasin \\ Kalimantan Selatan \\ akhmadgazali51@gmail.com
}

\author{
Jarkawi \\ Bimbingan Konseling \\ Universitas Islam Kalimantan MAB \\ Jalan adhyaksa No.2 Banjarmasin \\ Kalimantan Selatan \\ jarkawi010462@gmail.com
Muhammad Isran Ramli
Departemen Teknik Sipil
Universitas Hasanuddin
Sulawesi Selatan
isranramli@unhas.ac.id \\ Jl. Poros Malino Km. 6 Gowa
}

\begin{abstract}
Many factors cause traffic accidents where the driving speed is one of the main causes, this is known from several studies conducted in universities in the city of Banjarmasin which chronologically the accident events mostly stated that the vehicles involved in the accident were driven at high speed. The results of recording the speed on the road segment studied violations exceeding the speed limit that is at night before dawn, this applies to almost all types of vehicles in both directions of the lane at that time the traffic volume decreases. The majority of respondents think that high speed "speeding" is very likely $88.40 \%$ resulting in accidents that injure others and themselves. Regarding speed restrictions on all road segments to reduce accidents to the perpetrators respondents said $83.99 \%$ were subject to sanctions, and argued that the potential consequences of behavior beyond the speed limit were very harmful and dangerous, $71.7 \%$. And the main cause of motorists doing "speeding" is to reach their destination on time and even faster, $79.7 \%$.
\end{abstract}

Keywords: riders, speed, accidents, sanctions

\begin{abstract}
Abstrak
Banyak faktor penyebab kecelakaan lalu-lintas dimana kecepatan berkendaraan merupakan salah satu penyebab utamanya, ini diketahui dari beberapa penelitian yang dilakukan diperguruan tinggi di Kota Banjarmasin yang pada kronologis kejadian kecelakaannya sebagian besar menyebutkan bahwa kendaraan yang terlibat kecelakaan tersebut dipacu dengan kecepatan tinggi. Hasil dari pencatatan kecepatan pada segmen jalan yang diteliti terjadi pelanggaran melebihi batas kecepatan yaitu pada malam menjelang subuh, ini berlaku hampir pada semua jenis kendaraan dikedua arah jalur pada saat itu volume lalu-lintas berkurang. Mayoritas responden berpendapat bahwa berkecepatan tinggi "ngebut" sangat mungkin 88,40\% berakibat menyebabkan kecelakaan yang mencederai orang lain dan diri sendiri. Terkait dengan pembatasan kecepatan pada semua segmen jalan untuk mengurangi kecelakaan terhadap pelakunya responden mengatakan $83,99 \%$ dikenakan sanksi, serta berpendapat bahwa potensi akibat perilaku melampaui batas kecepatan sangat merugikan dan membahayakan, 71,7\%. Dan penyebab utama pengendara kendaraan bermotor melakukan "ngebut" adalah untuk mencapai tujuan tepat waktu dan bahkan bisa lebih cepat, 79,7\%.
\end{abstract}

Kata kunci: pengendara, ngebut, kecelakaan, sanksi 


\section{PENDAHULUAN}

Banyak faktor penyebab kecelakaan lalu-lintas yang antara lain adalah aspek fisik dari jalan tersebut, kendaraan yang dikendarai, perilaku pengendara serta faktor alam dan lingkungan. Laporan dari Kepolisian Lalu-lintas (Korlantas) Polri menunjukkan tingginyaangka kecelakaan yang terjadi dengan rata-rata rasio fatalis untuk 100.000 populasi nasional pada tahun 2016 sebesar 10,46. Disisi lain laporan Dekade Aksi Keselamatan Jalan 2011-2020 dan sustainable development goal menargetkan angka fatalis untuk negara dengan pemasukan menengah seperti Indonesia yaitu 7 kematian per 100.000 populasi. Penyebab kecelakaan yang terjadi didominasi oleh pelanggaran lalu-lintas, kurangnya kesadaran untuk berkendara secara bijak dan tertib serta penuh tanggung jawab khususnya untuk daerah Kalimantan Selatan yang luas wilayahnya adalah $38.744 \mathrm{~km}^{2}$ setara dengan sepertiga dari luas pulau jawa pada tahun 2018 jumlah penduduknya sebesar 4,12 juta jiwa, dari laporannya Subdit Gakkum Ditlantas Polda Kalsel tahun 2017 lalu tercatat ada sebanyak 454 jiwa melayang dari 569 kejadian kecelakaan, sedangkan pada tahun 2018 tercatat sebanyak 331 jiwa melayang di jalan akibat dari 526 kejadian kecelakaan, walau pun terjadi penurunan secara kuantitas angka kematian dalam kecelakaan pada tahun 2018 dibandingkan pada tahun sebelumnya 2017 namun angka kematian pada tahun 2018 tersebut dianggap cukup tinggi bila dibandingkan dengan penduduk wilayah Kalimantan Selatan yang hanya 4,12 juta jiwa. Bila mengacu pada laporan Dekade Aksi Keselamatan Jalan 2011-2020 dan sustainable development goal yang menargetkan angka fatalis untuk negara berkembang seperti Indonesia yaitu kurang lebih 7 kematian per 100.000 populasi, yang terjadi di wilayah Kalimantan Selatan ini angka fatalis mencapai lebih 8 kematian per 100.000 populasi. Kecepatan melampaui batas ketentuan merupakan salah satu penyebab terjadinya kecelakaan, diketahui dari penelitianpenelitian tentang kecelakaan di beberapa perguruan tinggi di Kota Banjarmasin, diantaranya menyebutkan dari kronologis kejadian kecelakaan di Provinsi Kalimantan Selatan dan Tengah tahun 2013 sampai 2017 disebutkan bahwa kecepatan melampaui batas sebagian besar merupakan penyebab dari terjadinya kecelakaan (Netti, 2017). Perilaku melampaui batas kecepatan ini juga diukur dengan melihat rerata kecepatan dan karakteristik kecepatan pada pengendara kendaraan bermotor (M Hustim, M Isran, 2013). Faktor kecepatan pada kendaraan ini sangat penting karena pada karakteristik lalu-lintas yang heterogen (Hustim, Ramli, 2018).

Penelitian ini bertujuan untuk mendapatkan nilai dasar dari indikator hubungan perilaku pengendara yang melampaui batas kecepatan terhadap potensi risiko terjadinya kecelakaan lalu-lintas pada ruas jalan nasional di Kota Banjarmasin dan memberikan rekomendasi kepada pemangku kepentingan untuk meningkatkan keselamatan dan keamanan berlalulintas.

\section{METODE PENELITIAN}

Metode yang digunakan dalam penelitian ini adalah dengan melakukan serangkaian survey lalu lintas yaitu, survey perhitungan volume lalu lintas, survey kecepatan, survey geometrik, dan survey wawancara, adapun lokasi penelitian dilakukan pada ruas jalan yang ada di Kota Banjarmasin dengan spesifikasi 6/2D yaitu Jalan Jenderal A. Yani Km.02.00 Km.08.00. 
Kondisi geometrik jalan yang diteliti sepanjang 6.000 meter adapun data geometrik lainnya seperti pada tabel 1, gambar 1 dan gambar 2.

Tabel 1. Data kondisi geometrik jalan

\begin{tabular}{|c|c|c|c|c|c|c|c|}
\hline & Titik & $\begin{array}{c}\text { Tipe } \\
\text { Jalan }\end{array}$ & $\begin{array}{l}\text { Lebar } \\
\text { Jalur }\end{array}$ & $\begin{array}{c}\text { Jumlah } \\
\text { Lajur }\end{array}$ & $\begin{array}{c}\text { Lebar } \\
\text { Lajur } \\
\text { (m) }\end{array}$ & $\begin{array}{c}\text { Lebar } \\
\text { Bahu } \\
\text { Jalan }\end{array}$ & $\begin{array}{c}\text { Lebar } \\
\text { Median }\end{array}$ \\
\hline \multirow{2}{*}{1} & Arah Keluar Kota & \multirow{2}{*}{$6 / 2 \mathrm{D}$} & 9 & 2 & 3 & 2,5 & \multirow{2}{*}{1,4} \\
\hline & Arah Kedalam Kota & & 9 & 2 & 3 & 2,5 & \\
\hline
\end{tabular}

Fasilitas jalan yang ada pada lokasi penelitian terdiri dari lampu jalan, median, marka jalan, bahu jalan, pohon pelindung dan saluran drainase. Kondisi fasilitas jalan yang ada pada lokasi penelitian ini masih dalam keadaan normal dan berfungsi dengan baik. Untuk kondisi lapangan terkait fasilitas jalan yang ada pada lokasi penelitian dapat terlihat pada tabel 1, gambar 1, gambar 2 dan gambar 3 berikut ini:

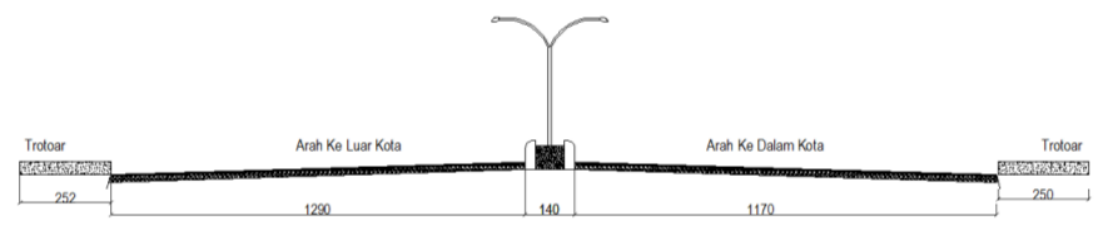

Gambar 1. Profile melintang Jalan A. Yani (Simp. Sugiono)

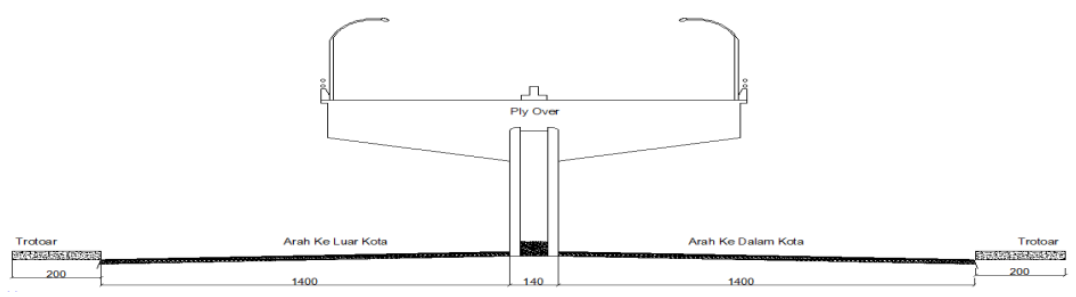

Gambar 2. Profile melintang Jalan A. Yani Fly Over

STA

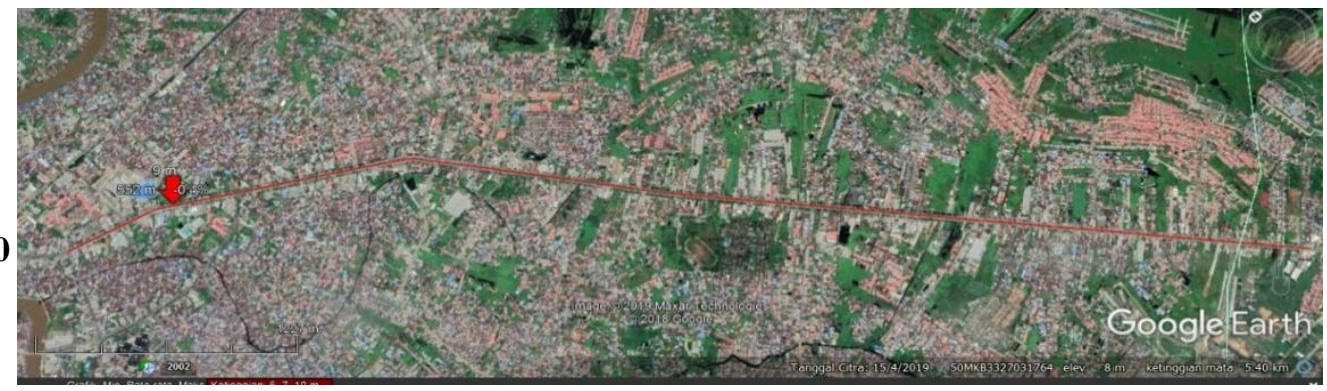

STA

Km.08.00

Km.02.00

Gambar 3. Lokasi penelitian

Pada gambar 1, gambar 2 dan gambar 3 terlihat bahwa kondisi ruas jalan lengkap dengan fasilitas yang memadai, kondisi perkerasan jalan juga baik dan tidak ada lubang atau retak 
sehingga sepanjang jarak lokasi penelitian nyaman bagi pengguna kendaraan untuk melintas dan sangat mendukung dalam melakukan penelitian.

\section{Survey Volume Lalu-lintas}

Survey volume lalu-lintas dilakukan selama 1 hari yaitu pada hari Rabu dimulai pada pukul 06.00 pagi dengan pencacahan setiap 15 menit dengan klasifikasi kendaraan, mengikuti golongan kendaraan menurut MKJI (sepeda motor, mobil, medium vehicle, dan heavy vehicle).

\section{Survey Kecepatan}

Survey kecepatan juga dilakukan dengan menggunakan pengamatan kecepatan melalui rekaman perjalanan kendaraan dengan menggunakan 2 buah handycam dengan jarak satu dengan yang lainnya 100 meter dilakukan selama 24 jam pada kedua arah jalan yaitu sepanjang $6 \mathrm{~km}$ dengan interval jarak tertentu sebanyak 30 sampel dan digunakan juga alat speed gun test untuk mengukur kecepatan dengan pemilihan acak semua jenis kendaraan di lapangan sebagai pembanding dari perhitungan kecepatan melalui rekaman perjalanan kendaraan.

\section{Survey Wawancara}

Survey wawancara ini untuk meneliti perilaku pengendara melalui wawancara dengan sejumlah pertanyaan-pertanyaan yang berkaitan dengan perilaku pengendara kendaraa bermotor yang memacu kendaraannya melampaui batas kecepatan yang ditentukan dan berpotensi menyebabkan kecelakaan, wawancara ini disebarkan melalui kuesioner online.

\section{Analisa Data}

Penelitian ini akan menggunakan 2 konsep psikologi yaitu risk taking culture, meliputi belief, sikap intensi, dan norma subjektif (Eiksund, 2009), dan risk perception, yaitu presepsi terhadap risiko kemungkinan terjadi kecelakaan lalu-lintas (Machin \& Sankey, 2007). Selain penggunaan kedua konsep tersebut diatas penelitian ini juga akan mengkaji nilai-nilai budaya yang berperan dalam mewarnai perilaku pengemudi di jalan raya. Pada penelitian ini menggunakan analisa deskriptif kualitatif dan kualitatif terhadap hasil wawancara dari semua responden serta perhitungan terhadap rerata kecepatan, mean, serta Level Of Service (LOS) dari kondisi ruas jalan komposisi kendaraan yang melintas serta validasi data kecepatan perilaku pengendara berdasarkan hasil kuesioner di lapangan menggunakan T-Test dan F-Test.

\section{HASIL DAN PEMBAHASAN}

\section{Karakteristik Geometrik dan Fasilitas Jalan di Lokasi Studi}

Jalan A. Yani Km.02.00 - Km.08.00 adalah salah satu jalan arteri dengan tipe 6/2 D (6 lajur, 2 arah, dan terbagi), menggunakan perkerasan lentur, dengan lebar lajur sama. Arus pergerakan lalu lintas dua arah yang dipisahkan oleh median dengan lebar 1,4 meter. 


\section{Karakteristik Volume Lalu Lintas}

Survey volume lalu lintas di ruas jalan dilakukan untuk mendapatkan data volume dan komposisi kendaraan. Volume lalu lintas dilakukan terpisah untuk masing-masing arah lalu lintas. Dalam survey ini kendaraan dikelompokkan mengikuti golongan kendaraan (MKJI 1997) berikut disajikan grafik data volume lalu-lintas pada ruas jalan yang diteliti.

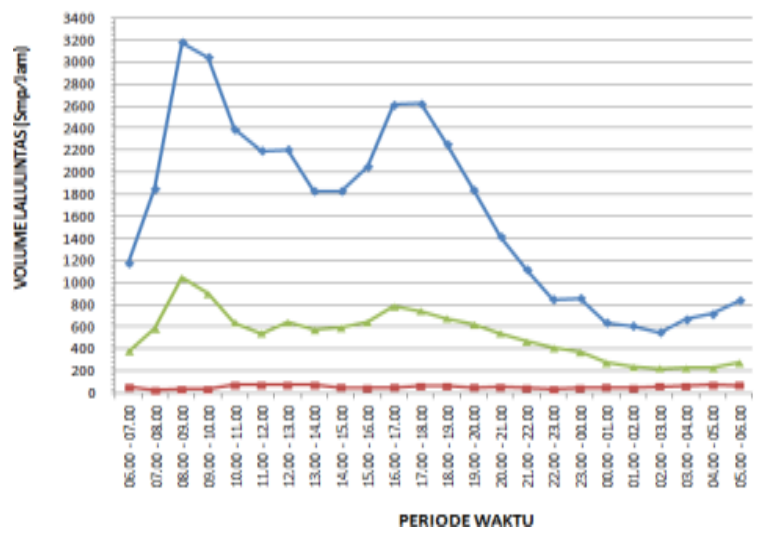

(a) Arah ke luar Kota Banjarmasin

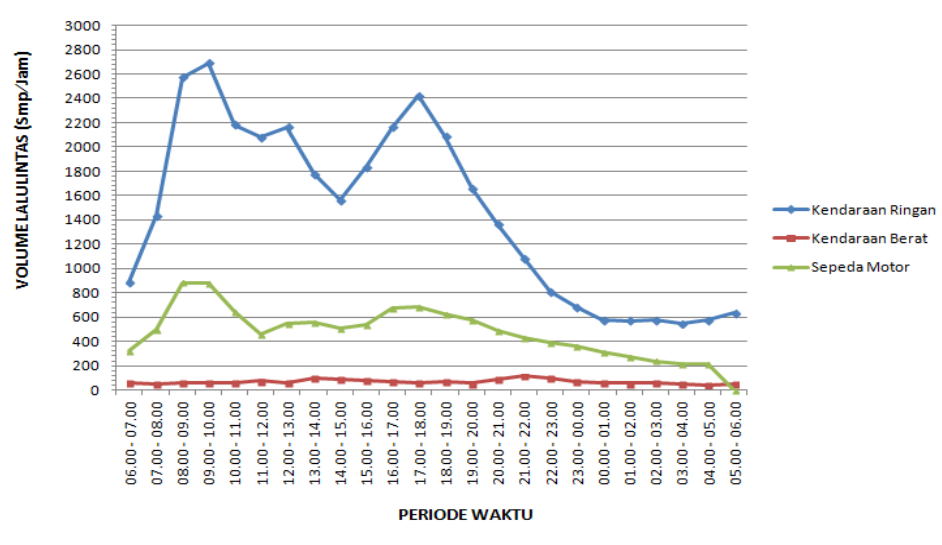

(b) Arah ke dalam Kota Banjarmasin

Gambar 4. Fluktuasi volume kendaraan

\section{Kecepatan Kendaraan}

Kecepatan Kendaraan yang melewati lokasi penelitian yaitu jalan A. Yani Km. 02.00 Km.08.00 dengan jumlah sampling sebanyak 30 per 2 jam, gambar berikut ini adalah kecepatan rerata kendaraan sampling.

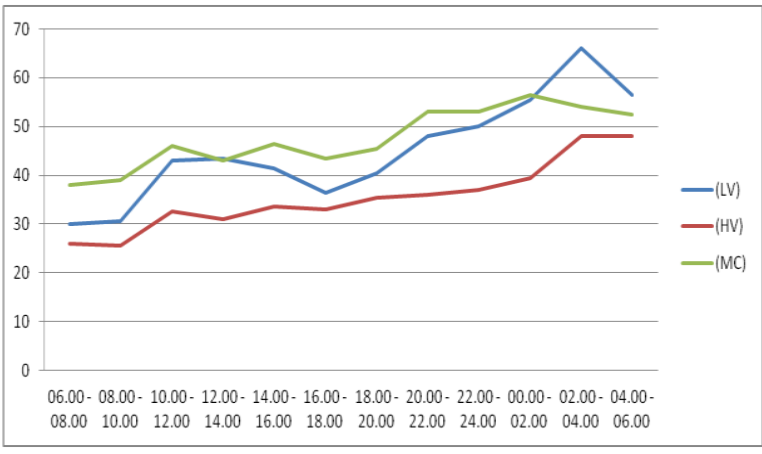

(a) Arah ke luar Kota Banjarmasin

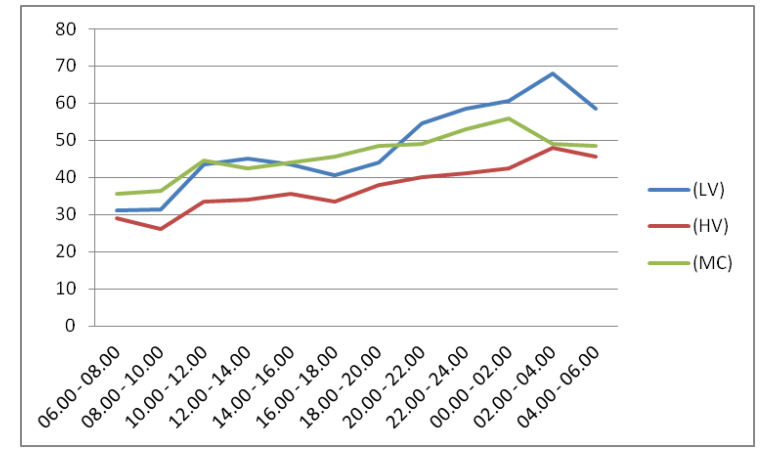

(b) Arah ke dalam Kota Banjarmasin

Gambar 5. Kecepatan rata-rata

Kecepatan kendaraan yang melampaui batas kecepatan maksimum yaitu diatas $60 \mathrm{~km} / \mathrm{jam}$ untuk jalan nasional terdiri atas beberapa kendaraan yang dominan melakukan hal tersebut yaitu pada malam hari hingga dini hari. Berikut adalah gambaran waktu jumlah kendaraan dengan kecepatan melampaui batas "ngebut", untuk arah keluar kota Banjarmasin pada periode waktu pagi sampai sore sebanyak 24 sampel atau sebesar $13,48 \%$ berupa sepeda motor dan kendaraan ringan dari keseluruhan sampel 178, sedangkan pada periode waktu malam sampai dini hari yaitu sebanyak 154 sampel atau sebesar $86,52 \%$. Untuk arah ke dalam kota Banjarmasin pada periode waktu pagi sampai sore sebanyak 24 sampel atau 
sebesar 12,83\% sepeda motor dan kendaraan ringan dari keseluruhan sampel 187, sedangkan pada periode waktu malam sampai dini hari yaitu sebanyak 163 sampel atau sebesar $87,17 \%$.

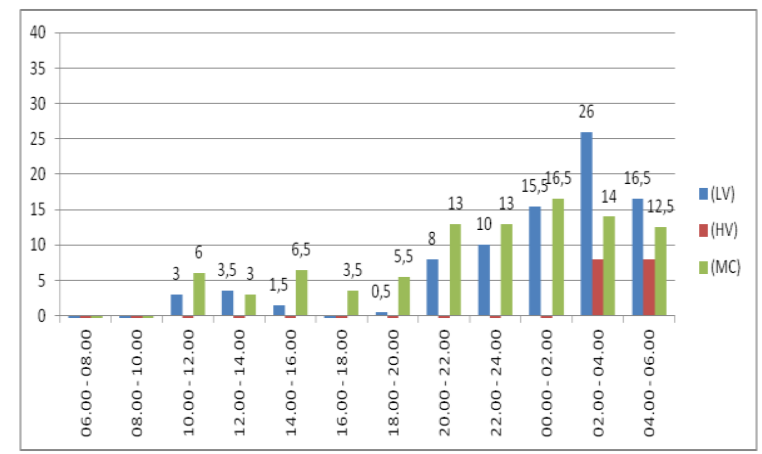

(a) Arah Ke Luar Kota Banjarmasin

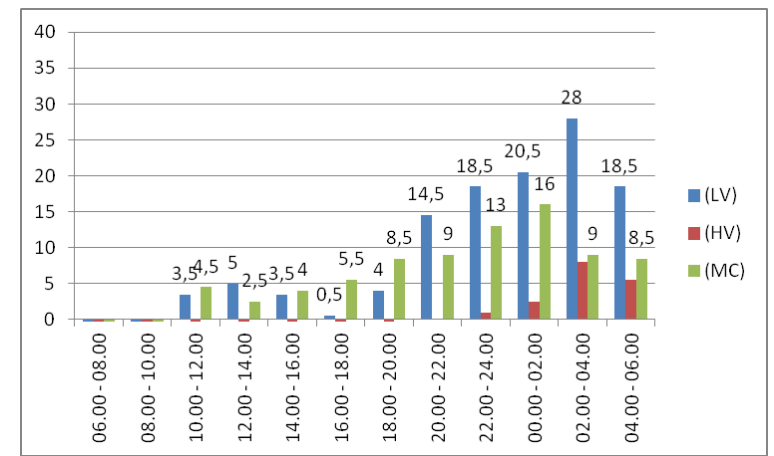

(b) Arah Ke Dalam Kota Banjarmasin

Gambar 6. Kecepatan melampaui

\section{Perilaku Pengendara}

Untuk mengetahui karakteristik perilaku pengendara kendaraan bermotor maka sejumlah pertanyaan telah diajukan kepada sejumlah responden hasilnya seperti pada gambar berikut dibawah ini:

1. Persentase Kecepatan Kebiasaan "Ngebut"

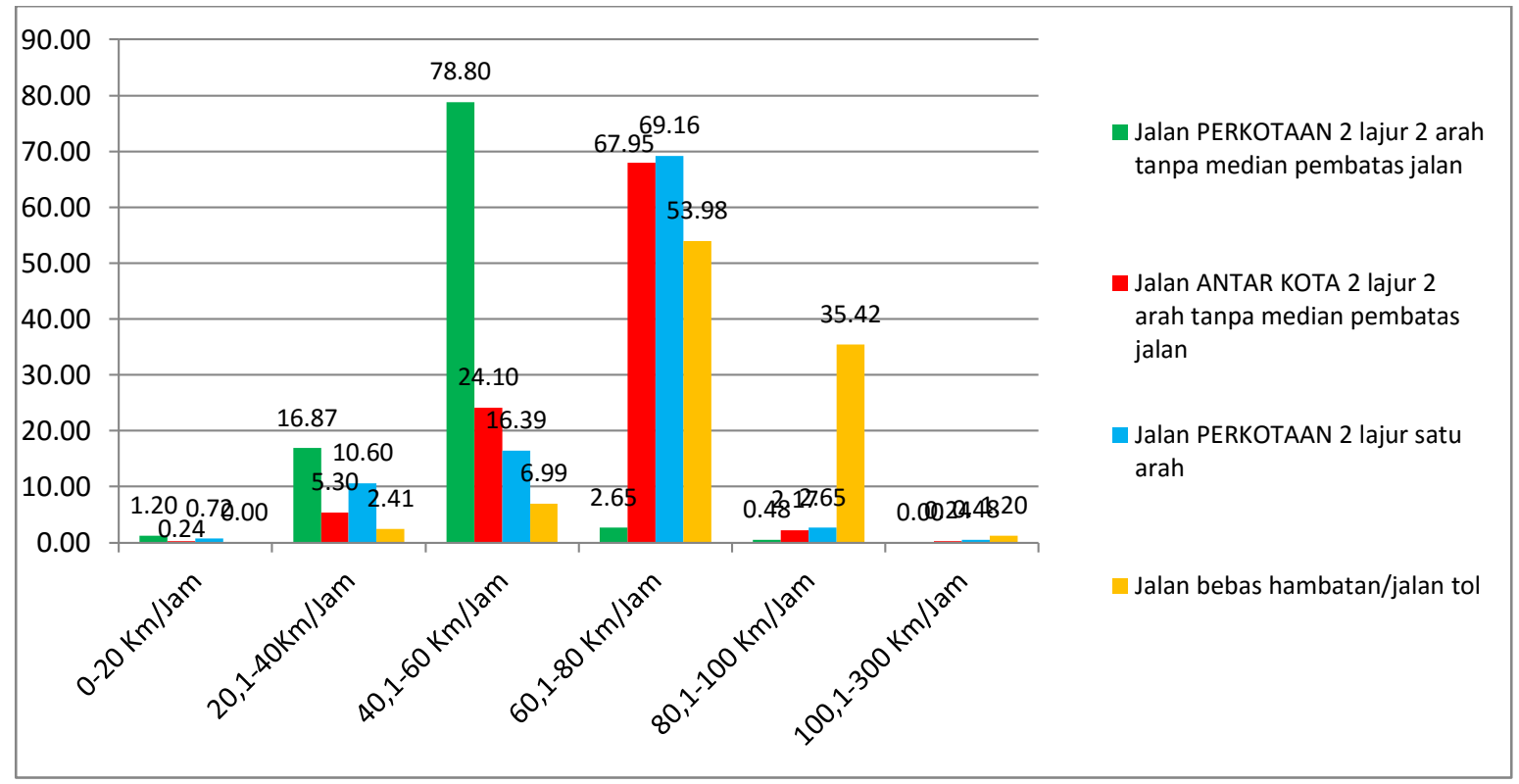

Gambar 7. Persentase kecepatan dengan kebiasaan "ngebut"

Pada gambar 7 ini memperlihatkan bahwa mayoritas kendaraan untuk jalan perkotaan yang menjadi pembanding untuk perilaku kecepatan berkendaraan berada pada kecepatan antara 40,1 km/jam - $60 \mathrm{~km} / \mathrm{jam}$, baik pada jalan perkotaan dengan atau tanpa terbagi. 
Data ini kemudian akan divalidasi dengan data kecepatan sampling yang diambil langsung di lapangan dan diuji variasi, sama, dan bedanya sehingga dapat terlihat jelas hubungan antara perilaku pengendara kendaraan bermotor yang ada di lapangan dengan asumsi atau pendapat dari responden melalui kuesioner online.

2. Persentase Pengaruh Kebiasaan "Ngebut" terhadap diri \& orang lain

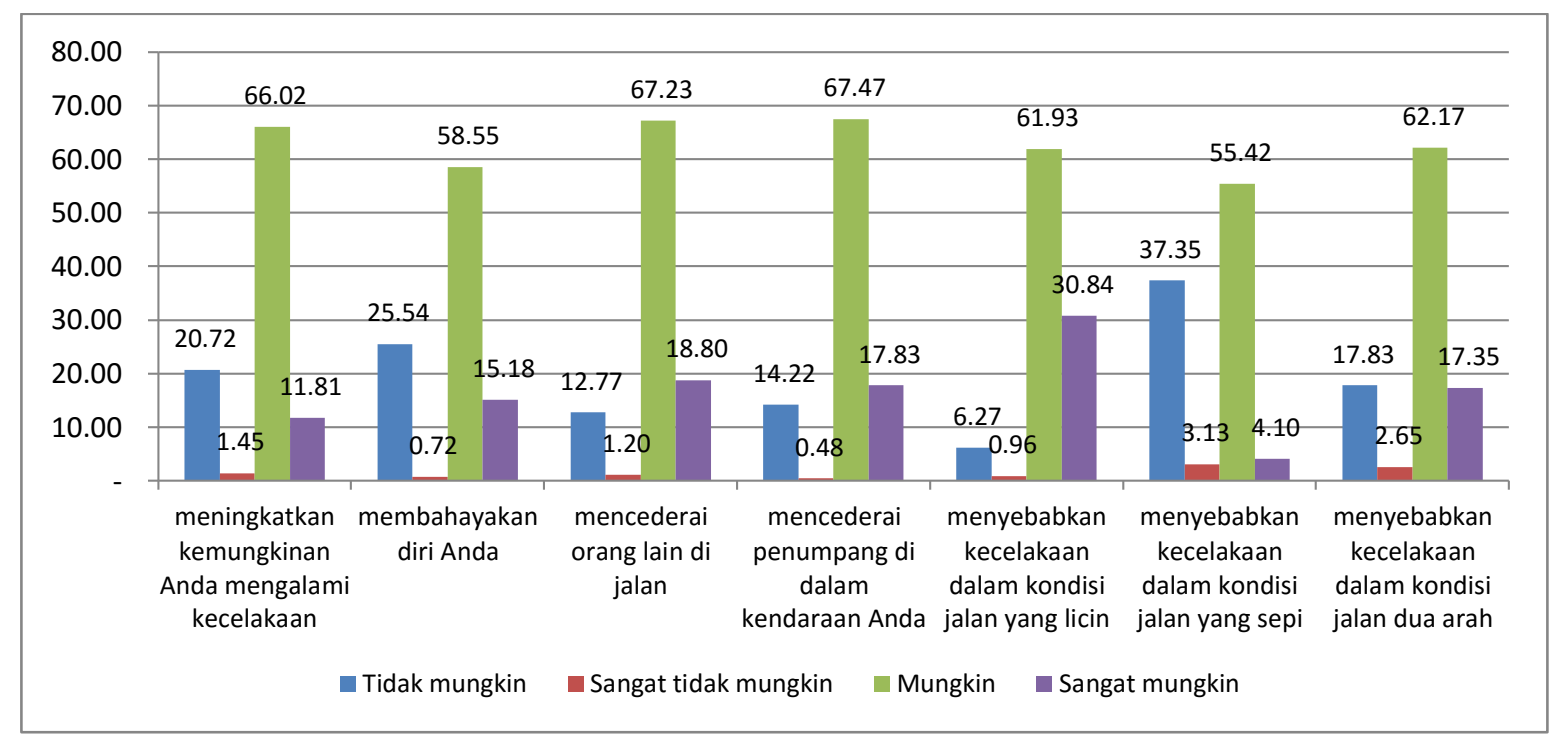

Gambar 8. Persentase pengaruh kebiasaan "ngebut"

3. Persentase Pendapat tentang "Ngebut"

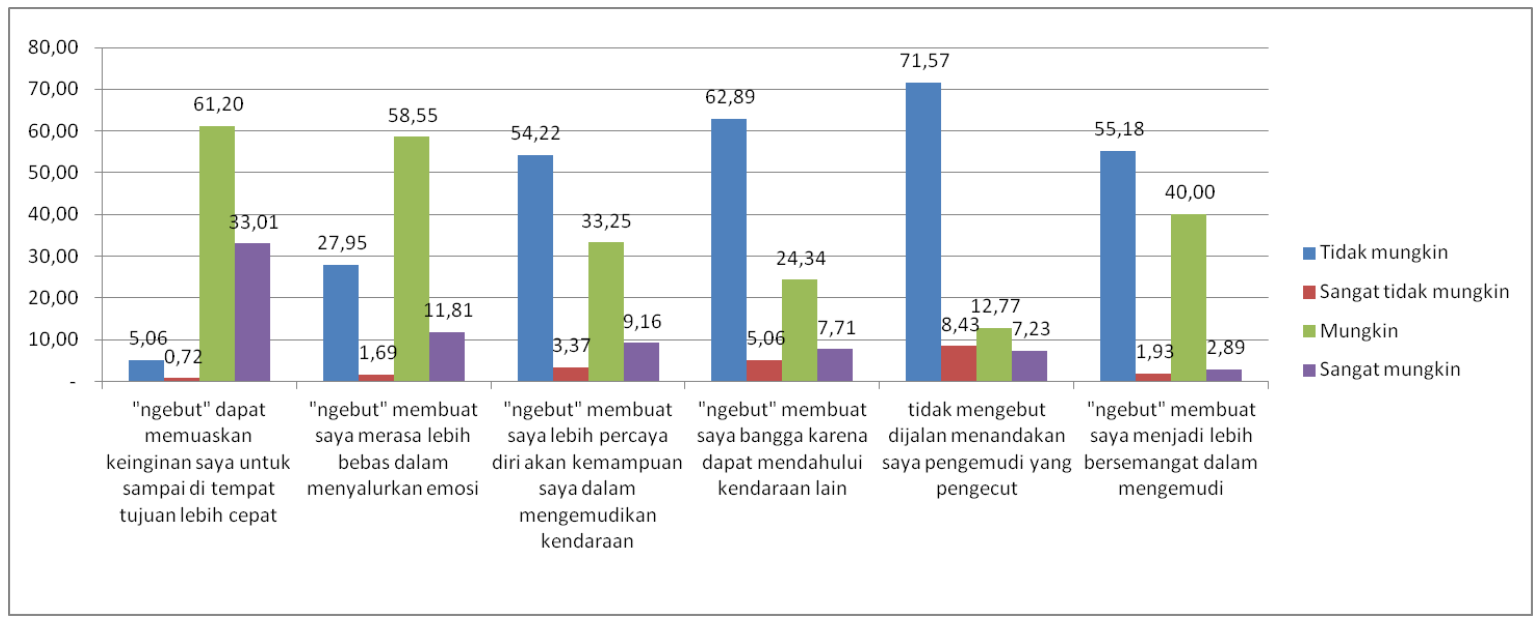

Gambar 9. Persentase pendapat tentang "ngebut"

\section{Hubungan Distribusi Kecepatan Dengan Perilaku Berkendaraan Dengan Kcepatan Tinggi "Ngebut"}

Kendaraan yang digunakan oleh pengendara kendaraan bermotor dengan kecepatan tinggi "ngebut" ini bervariasi. Terkait dengan perilaku atau kebiasaan ngebut, berikut ini adalah hubungan rerata kecepatan sampel lapangan dengan persepsi hasil kuesioner untuk kendaraan dari dua arah. 
1. Kecepatan Rata-rata "Ngebut" Kendaraan Ringan (LV) dan Berat (HV) Arah ke luar Kota Banjarmasin

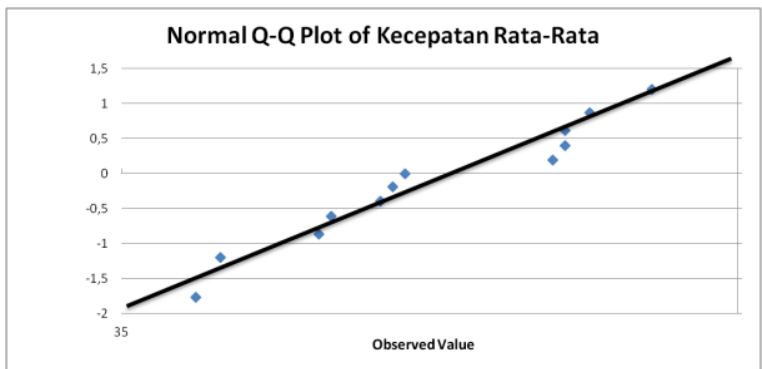

(a) Kendaraan ringan (LV)

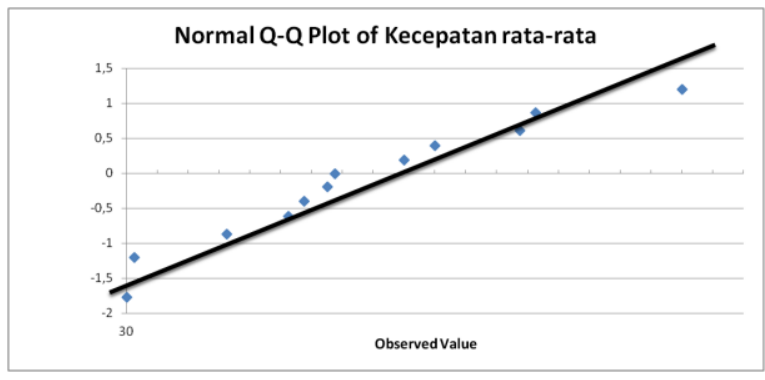

(b) Kendaraan berat (HV)

Gambar 10. Kecepatan rata-rata ngebut

2. Kecepatan Rata-rata "Ngebut" Kendaraan sepeda motor (MC) Arah ke luar Kota Banjarmasin

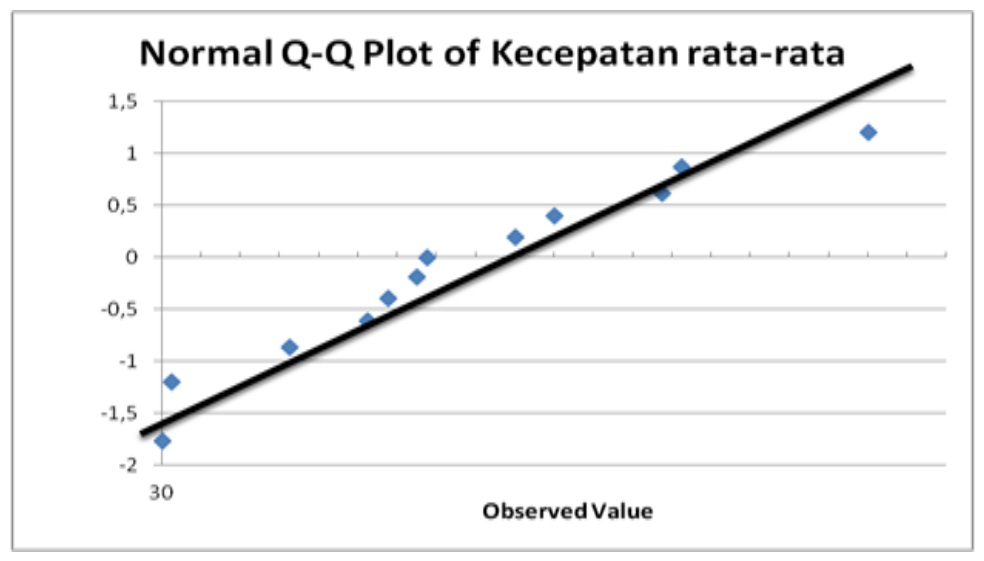

Gambar 11. Kecepatan rata-rata ngebut kendaraan sepeda motor (MC) arah ke luar Kota Banjarmasin

3. Kecepatan Rata-rata "Ngebut" Kendaraan Ringan (LV) dan Berat (HV) Arah ke dalam Kota Banjarmasin

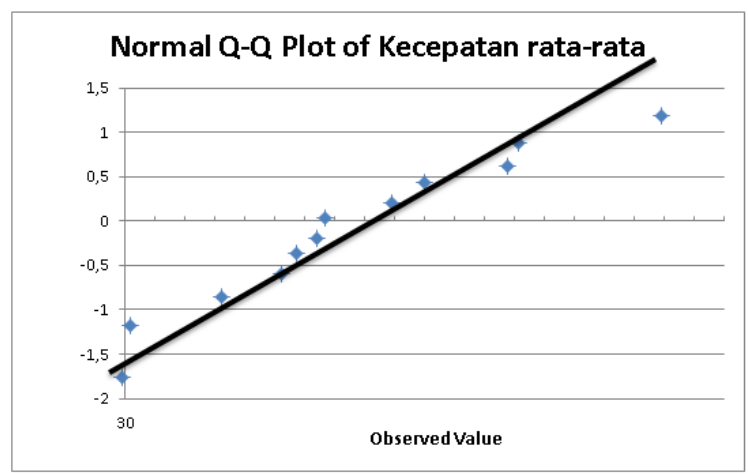

(a) Kendaraan ringan (LV)

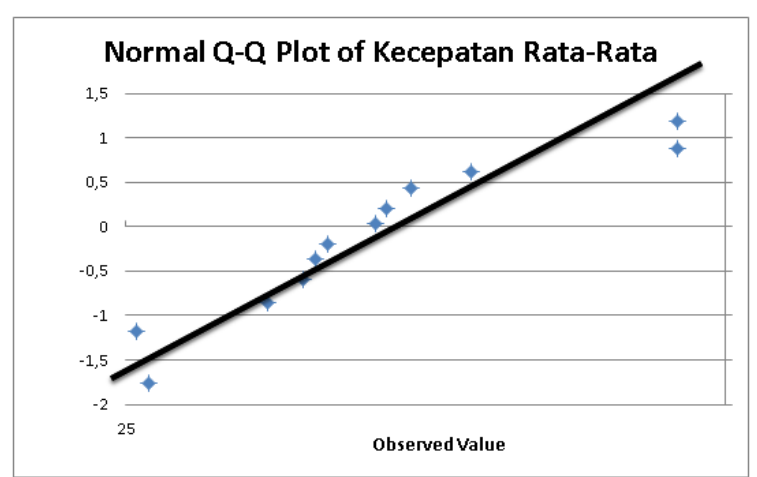

(b) Kendaraan berat (HV)

Gambar 12. Kecepatan rata-rata 
4. Kecepatan Rata-rata "Ngebut" Kendaraan sepeda motor (MC) Arah ke dalam Kota Banjarmasin

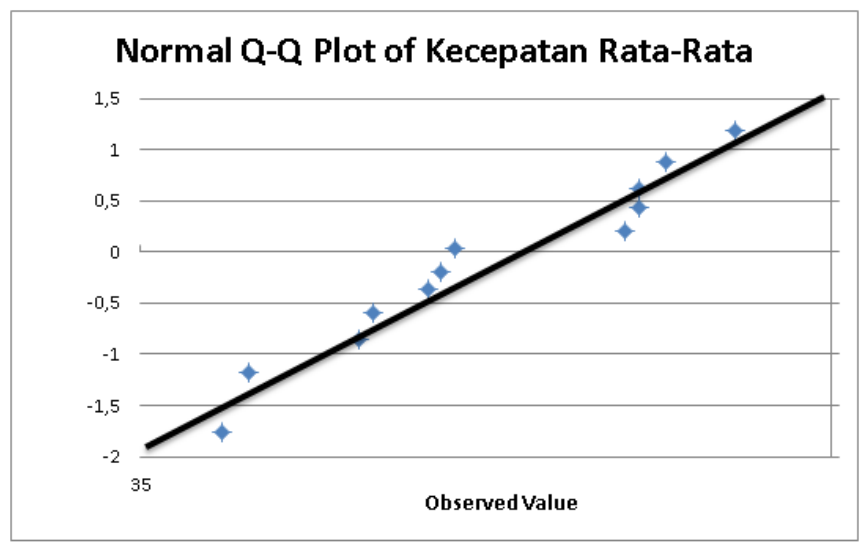

Gambar 13. Kecepatan rata-rata ngebut kendaraan sepeda motor (mc) arah ke dalam Kota Banjarmasin

Data normal plot dibutuhkan untuk melihat nilai yang merupakan observasi data lapangan yang kemudian dicocokkan dengan data survey wawancara. Hasil uji dari kedua kecepatan rata-rata yang terjadi, maka dilihat melalui nilai T-test dan F-test terkait uji persamaan antara kecepatan rata-rata lapangan dan persepsi masyarakat terkait perilaku ngebut atau melampaui batas kecepatan yang ada dan disajikan pada tabel berikut ini.

Tabel 2. Hasil uji statistik kecepatan lapangan dan kuesioner

\begin{tabular}{lcccccc}
\hline \multirow{2}{*}{ Hasil Uji } & \multicolumn{3}{c}{ Arah Ke Luar Kota } & \multicolumn{3}{c}{ Arah Ke Dalam Kota } \\
\cline { 2 - 6 } T-Test & LV & HV & MC & LV & HV & MC \\
\hline F-Test & 0,000 & 0,000 & 0,000 & 0,000 & 0,000 & 0,000 \\
\hline
\end{tabular}

Hasil uji T-Test menunjukkan bahwa kecepatan kendaraan sampel dengan persepsi responden relatif sama, nilai varians juga menunjukkan hasil yang dominan seragam namun sedikit variasi khususnya kendaraan berat dan sepeda motor. Hal ini dikarenakan ada sebagian kecil sampel yang melampui batas kecepatan pada periode waktu tertentu sehingga terjadi varians terhadap total sampel dan dengan persepsi kuesioner. Hasil uji F-Test > 0,05 menunjukkan bahwa data kecepatan lapangan memiliki varians yang sedikit beragam atau bervariasi dengan data kecepatan perilaku ngebut.

\section{PENUTUP}

\section{Kesimpulan}

Berdasarkan analisis dan pembahasan terkait perilaku "ngebut" pengendara kendaraan bermotor di Kota Banjarmasin, maka dapat disimpulkan beberapa hal sebagai berikut:

1. Dari pencatatan kecepatan pada segmen jalan yang diteliti di Kota Banjarmasin terjadi pelanggaran melebihi batas kecepatan yang ditentukan yaitu mulai pukul 20.00 - 
06.00 WITA atau malam hari sampai menjelang subuh, ini berlaku hampir pada semua jenis kendaraan dan pada kedua arah jalur, pada saat itu volume lalu-lintas dalam keadaan berkurang kepadatannya, dimana kecepatan maksimum untuk kendaraan ringan dapat mencapai $102 \mathrm{~km} / \mathrm{jam}$, kecepatan maksimum kendaraan berat $68 \mathrm{~km} / \mathrm{jam}$, dan kecepatan maksimum sepeda motor mencapai $80 \mathrm{~km} / \mathrm{jam}$ hal ini sangat berpotensi menyebabkan banyak terjadi kecelakaan.

2. Berdasarkan hasil wawancara, mayoritas responden memilih kecepatan kendaraan pada saat ngebut untuk jalan perkotaan berada pada kisaran 40,1 km/jam - $60 \mathrm{~km} / \mathrm{jam}$ dimana kecepatan ini relatif sama dengan kecepatan rata-rata seluruh jenis kendaraan dengan pengamatan langsung di lapangan yang berada pada kisaran $35 \mathrm{~km} / \mathrm{jam}-48$ $\mathrm{km} / \mathrm{jam}$.

3. Potensi kecelakaan akibat perilaku ngebut dengan melampaui batas kecepatan maksimum, mayoritas responden diatas $88,40 \%$ menjawab perilaku ini sangat merugikan dan dapat menyebabkan kecelakaan.

4. Terkait dengan pembatasan kecepatan pada semua segmen jalan untuk mengurangi kecelakaan terhadap pelakunya responden mengatakan 83,99\% dikenakan sanksi yaitu denda $42,17 \%$, pencabutan SIM sementara $74,22 \%$, sedangkan yang berpendapat masuk tahanan polisi cuma $12,29 \%$.

5. Mayoritas responden berpendapat bahwa potensi akibat perilaku melampaui batas kecepatan yang ditentukan sangat merugikan dan membahayakan, 71,7\%.

6. Mayoritas responden berpendapat penyebab utama pengendara kendaraan bermotor melakukan "ngebut" adalah untuk mencapai tujuan tepat waktu dan bahkan bisa lebih cepat lagi, $79,7 \%$.

\section{Saran}

Adapun sasaran dari penelitian adalah: Perilaku "ngebut" bagi pengendara kendaraan bermotor yang melampaui batas kecepatan maksimum banyak terjadi pada malam hari hingga dini hari sehingga meningkatkan potensi terjadinya kecelakaan maka perlu ada upaya-upaya untuk mengurangi potensi terjadinya kecelakaan tersebut yaitu dengan melakukan pengawasan, perbaikan utilitas jalan seperti marka jalan, rambu pengatur kecepatan, dan sebagainya agar tetap dapat meningkatkan kewaspadaan dan kehati-hatian bagi semua pengendara kendaraan bermotor.

\section{DAFTAR PUSTAKA}

Abdi, D. S. 2017, Studi Tingkat Kecelakaan lalu Lintas Jalan di Indonesia Berdasarkan Data KNKT (Komite Nasional Keselamatan Transportasi) Dari Tahun 2007 - 2016. Komite nasional Keselamatan Transportasi (KNKT).

Abdurrahman. H. 2018. Analisa Biaya Kerugian Kecelakaan Lalu-Lintas Jalan Raya Regional Provinsi Kalimantan Selatan, Kelompok Belajar Keahlian (KBK) Transportasi Fakultas Teknik Uniska.

Adisasmita, S. A. 2010. Perencanaan Jalan dan Jaringan Jalan. Makassar: Fakultas Perkapalan UNHAS.

Asian Development Bank. 1996. Road Safety Guidelines for the Asian and Pacific Region. Road Safety Seminar, Philippines.

Azis, M. A., Ramli, M. L, Aly, S. H., \& Hustim, M. 2013. The Motorcycle Driving Behaviors on Heterogeneous Traffic: The Real World Driving Cycle on the Urban 
Roads in Makassar. The 10th International Conference of Eastern Asia Society for Transportation Studies, Taipei.

David W. I. 2014. Mengurangi Resiko Kecelakaan Lalu Lintas Melalui Audit Keselamatan Jalan. Skripsi Teknik Sipil Fakultas Teknik Universitas Bengkulu.

Gito S., Mina Y. S. 2015. Karakteristik Kecelakaan Lalu Lintas dan Pendidikan Keselamatan Berlalulintas Sejak Usia Dini. Jurnal Ilmiah Semesta Teknika. Vol. 18 No. 1, 65 - 75, Mei 2015

Hasmar H. 2017. Kecelakaan Sepeda Motor di Kota Makassar. Jurnal Transportasi Vol. 17. No. 2 Agustus 2017: 155 -164.

Hudan R. 2018. Usaha Mereduksi Kecelakaan Lalu-lintas Jalan Raya Yang Diakibatkan Faktor Lingkungan, Jurnal Lembaga Penelitian dan Pengabdian Masyarakat (LPPM) ULM Banjarmasin.

Netti. 2017. Analisa Faktor Penyebab kecelakaan Lalu-lintas Jalan Pada Ruas Jalan Tamiang Layang - Ampah Kabupaten Barito Timur, Skripsi Program Studi Teknik Sipil Fakultas Teknik Uniska MAB.

Ni L. W. E. R. K, Indra S. 2017. Keselamatan Berlalu Lintas di Koa Bogor. Jurnal Manajemen Transportasi \& Logistik Vol. 4 No. 1, Maret 2017 - ISSN 2355-4721.

Nova, M. M. 2017. Hubungan Antara Faktor Keselamatan Berkendara dengan Perilaku Keselamatan Berkendara. Jurnal Promkes Vol. 5 No. 2 Desember 2017: 155 - 166 Pemerintah Republik Indonesia. 1993. Peraturan Pemerintah Republik Indonesia Nomor 43 Tahun 1993 Tentang Prasarana dan Lalu-lintas. Jakarta.

Pemerintah Republik Indonesia. 2009. Undang-Undang Republik Indonesia Nomor 22 Tahun 2009 Tentang Lalulintas dan Angkutan Jalan, n.d. Jakarta: Visimedia.

Prima J.R., Sholihin R. Pengaruh Kecepatan Kendaraan pada Keselamatan Pengguna Kendaraan Bermotor pada Simpang Tak Bersinyal. Jurnal Rekayasa Sipil Volume 11. No. 1-2-17 ISSN 1978-5658

Sjdberg, L., Moen, B.-E., \& Rundmo, T. 2004. Explaining Risk Perception. An Evaluation of the Psychometric Paradigm in Risk Perception Research. Trondheim: Norwegian University of Science and Technology, Department of Psychology.

Tasca, L. 2000. A Review of the Literature on Aggressive Driving Research. (Online), (http://www.stopandgo.org/research/aggressive/tasca.pdf., accessed Desember 25, 2015).

Unit Kecelakaan Lalulintas. 2017. Data Kecelakaan Lalu-lintas Kota Banjarmasin. Polresta Kota Banjarmasin.

Unit Kecelakaan Lalulintas. 2018. Data Kecelakaan Lalu-lintas Kota Banjarmasin. Polresta Kota Banjarmasin.

Zakaria, A., Aly, S. H., \& Ramli, I. M. 2011. Distribution Model of Motorcycle Speed on Divided Roadway in Makassar. The 14th FSTPT International Symposium, Pekanbaru. 